\title{
Fictional representation of prison in films and TV's series genre: public and academic perceptions of prison
}

\begin{abstract}
Imprisonment is a widespread punishment all over the world, but prison is for most of us an unknown experience and anything we know is mostly, through media and cinema representations. Therefore, it is very likely these representations play an important role in formation of our social representation for this matter. Additionally, the audience captivated for issues which are unknown and unreachable and that relate to the criminal behavior and action of institutions of social control of crime, but also to life in prison. In this article we will refer, firstly to the way of representation of prison in fictional films and television series, secondly the research which have been developed about the relationship between the fictional representation of prison and audience's reception and finally we will see what impact have all these to criminal justice community, since research saw that "skilled public" in criminological knowledge share the same perceptions for prison with others.
\end{abstract}

Keywords: prison, fictional representations, reception of audience, social construction, criminological knowledge
Volume 2 Issue I - 2016

Stavroula G Bougadi

Department of Sociology, Panteion University of Athens, Greece

Correspondence: Stavroula G Bougadi, PhD Researcher, Department of Sociology, Section of Criminology, Panteion University of Athens, Greece, Tel 6934456563 ,

Emailsbougadi@hotmail.com

Received: November 09, 2015 | Published: January II, 2016

\section{Introduction}

Media 'help' people in the construction of social reality. When, in fact it is a 'reality' as the prison, for which there is no information from other sources, is reasonable imaginary representations of the prison to exert greater influence on the public. According to Wilson et al., ${ }^{1}$ "prison drama provides 'an imaginative resource' that can demarcate audiences' limits of interpretations; evoke feelings of empathy; and ultimately inform their experience of prison". Moreover, when the Media mentioned the criminal justice system, the topics mainly concerns police and courts, rarely prisons. Generally, public learn about prison when there are riots, hunger strikes, escapes and releases or liberties of 'dangerous' inmates. In the most films on prison, it held out as a particularly dangerous area. These particularize to safety, threat and risk posed by even a visit to the prison, thus presented recurring scenes in which the visitor passes barbed wire, heavy iron doors, metal dividers and other frightening screens. On the other hand, we have very little evidence of perceptions about prison, of person with criminological knowledge ("skilled public"). Therefore, the aim of this article is not only to present the main characteristics of fictional representations of prison, but what are public's perceptions of prison and additionally to see if criminological knowledge play a role to above issues.

So, in order to understand all these, we will represent here, first the way in which media structure the fictional representations of prison and prisoners, secondly we will refer the relationship between the fictional representation of the prison and the audience's reception and finally we see what impact have all these to criminal justice community and especially to public with criminological knowledge. We have to clarify that, this is only a review glance of these issues and our aim is to draw the attention of researchers in these matters, in order this article to become a challenge for the continued discussion and research on these issues. The representation of the prison in movies is not new. Since the era of silent films were filmed on the subject of life in prison, about escapes and unjust sentences, creating in this way a successful recipe of following films unchanged until the decade of the ' 90 s. The Film of Prison (hereinafter FoP), since it first appeared, is very popular and this happens, according to Rafter ${ }^{2}$ because they cover four needs of audiences:
i. Self-identification with their heroes or super-hero
ii. Participation in the perfect friendship: as it is filled with the ideal companions who may have
iii. Offering sexual phantasy: both heterosexual and homosexual and
iv. Satisfaction of curiosity about life behind bars, as most claim that they are based on true story. ${ }^{2}$

The same happens with TV's series representation of the prison and generally the penal system where they emerge from the ' 50 s. The 70s arrive at their zenith and their subjects were mainly crime and justice. During the 80 s were dominated by detectives, private investigators and the female figures in leading roles. In the same time Media continue to offer the general subject of the penal system, which is presented as dysfunctional and contemporaneously suggesting alternative treatment for crime's victims. It is interesting that these illustrations are displayed at the time of the US government of Ronald Reagan, where the crimes control towers and prevailing harsh politics against offenders. ${ }^{3}$ In the 90 s some new television series offers viewers more realistic depictions of the criminal justice system than in the past and usually have divided into two sections: one was about police investigation and the other about the process of prosecution. At the same time, appearing as protagonists' special criminal intelligence, investigators (forensic experts), psychologists and forensic medical experts, ${ }^{4}$ and since 2000 onwards are appearing more intensely. ${ }^{5}$ 


\section{Contemporary research about cinema and television representations of prison}

In recent years, scholars have turned their interest to examine both the 'factual and the fictional representation of the prison on media and how these can affect the public's perception of the prison and prisoners. It has been argued that the steady increasing observed in prison population since 90 s until today in the US, UK but also in the rest of Europe, is associated with the panic which have been causing by the Media and its propaganda about the "myths of prison". Moreover, criminologist maintain that films whose issue is about crime tend to reflect criminological theories, or better, the criminological theories which is contemporary when these films produced. Melossi ${ }^{6}$ argued that the criminological discourse and artistic representations of the criminal and the punishment following the same social reformation process. In particular, he argued that there is an affinity between the social processes that increase the number of inmates and those that change the representation of the criminal. Actually, it is the same social process, in which the altered representation-social action-orienting makes it possible to increase or decrease numbers and oscillation of numbers, in turn, affects the quality of representation. Scholars argue that the distorted image of the prison, showing the media, contributes to misunderstanding of the public about the nature of this institution, reinforces the popular support of its faille and additionally researchers are pessimistic whether this negative effect can change.

Generally, it is argued that fictionalized representations of the prison have not contributed to public understanding of the prison, and do not contribute positively in the direction of improving it. ${ }^{7}$ This is because the entertainment television industry has transformed crime and jail entertaining objects, thus eroding our doubts and concerns about the prison as a solution of crime reduction. This is happen because the entertainment television's industry has transformed crime and jail in entertaining objects. ${ }^{8}$ The fictional representation of prison in cinema, the last decade ,manufactures prison not only as necessary punishment but also as an unique process for the control and reduction of crime, in order to eliminate these "others" misfits, "psychotic criminals". Therefore argued that the extension of the super maximum security's prison facilities is legitimized by the publication of the media, in order to control "the worst of the worst" of the incarcerated population who requires draconian measures to manage and reduce them. This construction is a misrepresentation characteristics of prisoners as not only contribute to the formation of public knowledge to imprisonment but convincing the public that knows what's going to prison ${ }^{9}$ and thus reinforce the need for the existence and expansion of the sentence of imprisonment while alternative penalties apply in practice or emerge by media are rare.

In 2001 O'Sullivan ${ }^{10}$ studied four films relating to prison. All of them were Hollywood productions encountered during the decade of the '90 (The Shawshank Redemption1994, American History 1998, Convict Cowboy 1995, Con Air 1997) and he concludes that : all these films focusing on dangerous offenders serving long sentences ('higher tariff offenders') and provide misrepresentations of prisoners and the offenses they have committed. In addition, all films tacitly accept imprisonment as a necessary part of the criminal justice system. None poses radical criticism of imprisonment and none articulates grounds relating to the concerns of Mathiesen ${ }^{8}$ on the increase of prison population and the social construction of a 'prison fiasco' (failed institution). ${ }^{8}$ As we know, the messages of the media are polysemic. Also, the concepts of authors of fiction films and series are open to different recruitment from audience, which receives information from other sources (direct or indirect experience). With this in mind, we understand the importance of research for recruitment to the public on representations of the prison and prisoners.

According to a survey (January-March 2002) conducted by the Open University in Britain, under the program "Rethinking Crime and Punishment" (RCP), ${ }^{11}$ which examined how the media formatting the views of the public from 'knowledge' that it obtains from the fictional representations of crime (movies, soaps, documentary- dramas) but also documentaries, news and broadcasts relating to imprisonment, showed that viewers agreed that television and radio make them think that prison is the only solution for the most serious crimes. A significant minority of viewers claimed to be less punitive when knowing the background history of the offender. A part from this, the personal experience, either as a victim of a crime or when know someone who has fallen victim to crime, plays an important role in how the person interprets the crime scene in the media. The interpretation of stories about crime and punishment is both individual and social activity as people interact and exchange views. Finally, according to the above research, the knowledge of onlookers formed more than fictionalized representations of crime assisted by direct or indirect experiences, rather than the 'real' programs of Media. This happens, since news have a more ephemeral impact while films excite the imagination.

\section{Academic criminological knowledge and public perceptions for prison}

As we already noted the general public do not know what really happen in prison, but watching fictional representations of prison can structures their perceptions about prison and prisoners. Also, we mentioned above that fictional representations of crime and prison reflect the contemporary criminological theories. But, what happen with the "experts"? Have "skilled public" (academics of criminology or criminal justice) the same perceptions for prison with other public, which have not any academic criminological knowledge? According to Bennett ${ }^{12}$ Media play three key roles in fictionalized representations:

i. Devising, giving general background of prison or showing reactions of the community.

ii. Comparison, allowing the 'benchmark', both for moral elevation and the authenticity and sets the limits of acceptance pressing behavior and

iii. The prism through which we 'see' the prison. With other words, the films reflect the academic explanation: this display of Media forming our social construction of reality in a way that distorted reality. ${ }^{12}$

Moreover, according to Miller et al., ${ }^{13}$ who investigated the perceptions of students, whom the object of study concerned the criminal justice, on the accuracy of the information about the criminal justice system, concluded that the majority of students did not have exact knowledge of criminal justice system. Even if the researchers have argued that the inaccurate picture of the criminal justice system by students of the area, comes from the distortions of recreational representations of media they also highlighted that the reasons for this is not clear. They argued, however, it was clear that the university education does not seem to clear up these issues to students. Specifically, they examined the perceptions of criminal justice and criminology students and non-students, to the six following key topics often presented in entertainment Media in US: the number of homicides each year, the number of prisoners, the number of inmates who killed by other inmates annually, the number of prison 
staff killed by prisoners each year, the percentage of male prisoners have consented to engage in sexual activities and the percentage of prisoners-victims of sexual assault.

The results showed that in all six issues students of criminal justice were not aware of actual situation instead were poorly informed of the representations of the media, as well as students who are not specializing in domain of criminal justice. In our small scale qualitative research ${ }^{14}$ we also reach to the same result, as above: academic criminological knowledge does not prevent 'experts' by the media and common constructive image for prison and prisoners. Taking individual interviews of two groups, consisting of 5 persons each: a group of "skilled public" and a group of "unskilled public", regarding its criminological knowledge, throughout general questions about prison and in particular for the TV series 'Prison Break', and by using qualitative content analysis that start with thematic coding and ends up with a thematic structure ${ }^{15}$ we try to explore the views of both on prison and prisoners. Our results showed that criminological education helps qualified audience ("skilled public") to use scientific terminology and expresses its views with more confidence than the 'unskilled public'.

However, finally criminological knowledge didn't play a catalytic role, in order to alter significantly the socially constructed attitudes for prison and prisoners. Eventually, both groups have shared the same perceptions for prison, not denied the existence of the prison, in contrary, accepted the deprivation of freedom as an appropriate form of punishment. In other words, the above findings saw us that even criminological knowledge is not enough to overcome the constructed image of crime and punishment. Even if we can't generalize these findings, since our sample is limited and therefore does not 'reaches' to theoretical saturation, we wonder that academic education, probably, does not compensate for the effects of 'knowledge' from the representations of the media. That is, presumably, because the academic knowledge is not the only source, that students obtain information about the operation of the penal system, but they 'learn' about it from other sources, such as their own experience or the experiences of others who are socialized with, but also and mostly by the media, where this' learning ' based on stereotypes and fictional allegations.

Actually, we need more research to this issue, as these results seem likely to contain a serious risking, owing to the fact that students of criminal justice and criminology do not have a realistic perception of crime and punishment. So, when they are going to work in the criminal justice system, their actions will not be sprigged by a pragmatic knowledge, but by the generalized conceptions of media and constructive Knowledge. Thus, we understand the important role that fictionalized representations of prison and prisoners are play in social and academic constructions-on the ground that there is a feedback between them-and how essential is, firstly the alternative representation of offender's punishment by the Media and secondly carrying out more research, in order to understand better their crucial role.

\section{Conclusion}

In conclusion, although fictionalized representations of prison by the Media can raise issues about the administration of justice, finally do not deny the existence of the criminal justice system, particularly prison as appropriate form of punishment. By contrast, the representation of the prison by the media reinforces the industrial development of prisons in countries like Britain and the US, where injustice, cruelty, inefficiency and malfunction, remains endemic, while the public, with few opposing representations, have no objection and thus completely expresses its approval for the use of imprisonment as acceptable form of crime control. Moreover, very important is the expansion of knowledge of specialist public in criminological issues, because a holistic and pragmatic approach of the criminal justice system, which they will serve, could break up fictionalized perceptions about prison and prisoners.

\section{Acknowledgments}

None.

\section{Conflicts of interest}

The author declares that there are no conflicts of interest.

\section{References}

1. Wilson D, Sullivan OS. Images of Incarceration: Representations of Prison in Film and Television Drama. Waterside Press. 2004;192 p.

2. Rafter N. Shots in the Mirror, Crime films and society, 2nd ed. Oxford University Press, Oxford, New York, USA. 2006;265 p.

3. Dowler K. Introduction to the Special Issue: Media Criminology in the Television World. Journal of Criminal Justice and Popular Culture. 2007;14(3):237-242.

4. For example TV series. Law and Order, since 1990 and NYPD, since 1993.

5. For example TV series. CSI: Crime Scene Investigation, start in 2000, Law and Order: Criminal Intent 2001, Miami 2002, Criminal Minds 2005, Bones 2005

6. Melossi D. Changing Representations of the Criminal. Br J Criminol. 2000;40(2):296-320.

7. Mason P. Lies, distortion and what doesn't work: Monitoring prison stories in the British media. Crime Media Culture. 2006;2(3):251-267.

8. Mathiesen Th. Television, public space and prison population. Punishment \& Society. 2001;3(1):35-42.

9. Mason P. Prison Decayed: Cinematic Penal Discourse and Populism 1995-2005. Social Semiotics. 2006;16(4):607-626.

10. Sullivan OS. Representations of Prison in Nineties Hollywood Cinema: From Con Air to the Shawshank Redemption. The Howard Journal of Criminal Justice. 2001;40(4):317-334.

11. Gillespie M, McLaughlin E. Media and the shaping of public knowledge and attitudes towards crime and punishment. Rethinking Crime \& Punishment, London, UK. 2003.

12. Bennett J. The Good, the Bad and Ugly: The Media in Prison Films. The Howard Journal of Criminal Justice. 2006;45(2):97-115.

13. Miller JA, Tewksbury R, Hensley C. College Student's Perceptions of Crime, Prison and Prisoners, Criminal Justice Studies. A Critical Journal of Crime, Law and Society. 2004;17(3):311-328.

14. Bougadi SG. Anniversary Symposium 30 years of Postgraduate Seminar in Criminology \& 10 years of Programme of Postgraduate Studies: The Contemporary Criminality and its Confrontation, Presentations and Representations of Prison. The case of television's series 'Prison Break'. Panteion University of Athens, Greece. 2013.

15. Flick U. An Introduction to Qualitative Research, 3rd ed. Sage Publications, London, UK. 1998;150-171 p. 